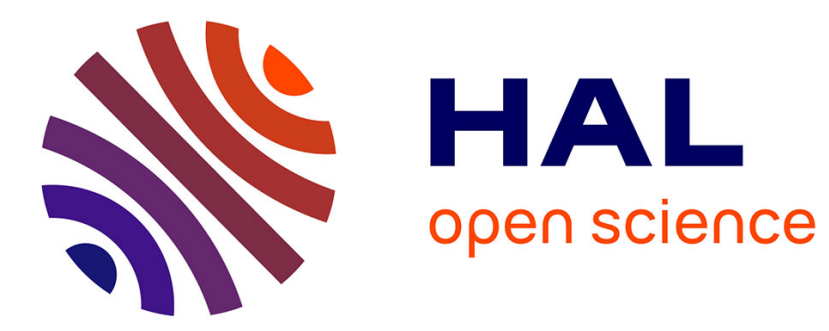

\title{
The post-Macy paradox, information management and organising: Good intentions and a road to hell?
}

François-Xavier de Vaujany, Nathalie Mitev

\section{To cite this version:}

François-Xavier de Vaujany, Nathalie Mitev. The post-Macy paradox, information management and organising: Good intentions and a road to hell?. Culture and Organization, 2015, 21 (5), 10.1080/14759551.2015.1103242. hal-01215546

\author{
HAL Id: hal-01215546 \\ https://hal.science/hal-01215546
}

Submitted on 14 Oct 2015

HAL is a multi-disciplinary open access archive for the deposit and dissemination of scientific research documents, whether they are published or not. The documents may come from teaching and research institutions in France or abroad, or from public or private research centers.
L'archive ouverte pluridisciplinaire HAL, est destinée au dépôt et à la diffusion de documents scientifiques de niveau recherche, publiés ou non, émanant des établissements d'enseignement et de recherche français ou étrangers, des laboratoires publics ou privés. 


\title{
RESEARCH ARTICLE
}

\section{The post-Macy paradox, information management and organising:}

\section{Good intentions and a road to hell?}

François-Xavier de Vaujany

DRM (UMR CNRS 7088)

PSL-Université Paris-Dauphine

devaujany@dauphine.fr

\author{
Nathalie Mitev \\ Department of Management \\ King's College London \\ nmitev@btinternet.com
}

\begin{abstract}
Between 1946 and 1953, leading scientists met in New York in the context of the so-called 'Macy conferences', often linked to the emergence of cybernetics. They hankered for a new vision of mind and society. The traumatism of WW2 was implicit but omnipresent, and the Cold War was beginning. Macy key tools and concepts about information, the value of information, and computer artefacts have finally produced a new world, in particular an organisational world, which is far removed from their original dreams. Organisational members are now involved in difficult situations in terms of organising, i.e. new modes of performativity which are difficult to comprehend and deal with; a transformation of meaning and knowledge in collective activity; and a threat to well-being and happiness as mental activities, cognition and bodies are increasingly disconnected. We use the Macy conferences as an entry point to reflect on the 'longue durée' evolution of the material underpinnings of information and their relationship with organising. We first explore the new conceptualisations at the core of the Macy conferences, information, value of information, and computer artefacts. We then put the Macy conferences into a socio-historical perspective by means of two theoretical approaches, iconographical and semiotic; this involves a historical comparison between the 'screen-images' or our Information Age and the 'object-images' of medieval cathedrals. We show that there are important disruptions in organising grounded in a new semiosis which emerged over the longue durée of collective activity, and was articulated further during the Macy conferences. We describe this long-term evolution as the post-Macy paradox.
\end{abstract}

\section{Keywords}

Information; Macy conferences; post-Macy paradox; materiality; object-images; screen-images; history; semiosis; organizing 


\section{Introduction: an historical perspective on information and materiality in society and organisations}

Information is perceived to be at the heart of society and organisations (Gleick 2012). The concept of information itself and its emergence have been analysed by many authors and some from a historical perspective. For instance Wright (2007) adopts a genealogical perspective to show that the problems we have with information categorization, storage, and overload are anything but new. Black, Muddiman, and Plant (2007) present a historical account which questions the novelty of the current information society (see also [Webster 2007]); they trace the origins of the Information Age in Britain, the history in which a national information infrastructure was established between the late 19th century and the 1930s, when information professions came into being; just because the period is 'pre-computer' does not mean that it was an information 'dark age'. Lamoreaux and Raff (2007)'s work on information and organisation provides material for business historians and economists to study the development of the dissemination of information and the coordination of economic activity within and between firms. Day (2008) provides a historically informed critical analysis of the concept and politics of information. He explores the relation of critical theory and information, particularly in regard to the information culture's transformation of history, historiography and historicity into positive categories of assumed and represented knowledge. Day concludes his book with a challenge, calling on readers to rethink how information is constructed and to ponder how serious the stakes surrounding this term have become, in the face of social forces that seek to reduce information to nothing more than a thing that can be bought and sold. In an unusual science-fiction novel, Case (1997) prophesises that people will lose trust in information media and understand that there are no universal truths in the information they are confronted with. In his imagined future, people create a utopia devoid of sophisticated information and communication media.

Today, information is sometimes seen as a core evil with people having to cope with an information explosion and information overload (Simon 1990, 1996; Edmunds and Morris 2000; Rosenberg 2003; Allen and Wilson 2003; Eppler and Mengis 2004); or others concentrating on their right to information or their right to digital forgetting (MayerSchönberger 2011; Rallet and Rochelandet 2011), highlighting the contradiction between the perfect remembering possible through digital technologies and its negative and increasingly damaging effects. Information has become such a key notion that one can even define capitalism via the "economics of information" or "economics of knowledge" (Boisot 1998; Castells 2000).

However, the theorisation of information, materiality and organising are rarely looked at together, in particular from both an historical and a critical perspective. Much work has been done on materiality and technology in organisations, particularly the material role of information technology and information systems in organising (see, e.g., [Orlikowski 2007; Leonardi and Barley 2008; Doolin and McLeod 2012; Leclercq et al. 2009; Leonardi 2012]). Recently, some have shown an interest more specifically on materiality and information. 
Boell and Cecez-Kecmanovic (2011) propose a sociomaterial and performative account of information according to which information is seen to create reality rather than simply represent it. Crowston and Østerlund (2013) concentrate on the changing notion of document as a lens into the sociomaterial nature of what organisational members do day in and day out. Robertson (2014) also analyses paper-based media as a technology, how their relation to identity is about the materiality of information and shows how distinct practices of use create specific relationships between technology and information. Here we propose to step back and start from the conceptualisation of information, revisit its historical materialisations and analyse the organizing implications.

Information and its changing material underpinnings and imagery are at the core of contemporary organising and its "obsessions with storage, visualization and interactivity in digital systems" (Halpern 2014). We propose to concentrate their analysis through distinguishing three major disruptions in organising ${ }^{1}$ : (1) new modes of performativity which are difficult to comprehend and deal with, in particular in the context of managerial practices; (2) a transformation of meaning and knowledge in collective activities; and (3) a threat to well-being and happiness as mental activities, individual and collective cognition, and bodies are increasingly disconnected. We will explore in this article what we call the "post-Macy paradox" and these three associated disruptions in organising. We will focus on the micro-social and organisational implications of an initial dream which may turn gradually into a nightmare.

We first return to the notion of information and its relationship with materiality by adopting a historical posture from the perspective of an emblematic event ${ }^{2}$, the Macy conferences (1946-1953) in order to better understand the place of information and materiality in contemporary societies and organisations, and explore the nature of the information explosion and its implications. Dourish and Mazmanian (2013) are some of the few who have already focused on the links between information and materiality. They state that the ways in which information is understood "carry implications for organizational processes and social practice" (Dourish and Mazmanian 2013, 99). They conceptualise information and its relationship with materiality in the following five ways.

- As a "material culture of digital goods" focused on their symbolic value;

- As a "transformative materiality of digital goods", which emphasises the commoditisation and material or spatial underpinnings of IT, IT infrastructures and IT markets;

\footnotetext{
${ }^{1}$ We will use the notion of organising in the pragmatist sense of Lorino, Tricard and Clot (2011, 775): "Organizing will be viewed here as a collective activity, i.e. the permanent collective effort to transform the world and at the same time interpret this effort reflexively."

${ }^{2}$ The Macy conferences themselves are not a brutal, single, turning point in the conceptualisation of meaning and information. Many other events before and after have contributed to a standardisation of writing and knowing, the architecture of computers and the cybernetic turn (see also Pickering 2002, 2010). Nonetheless, the Macy conferences epitomise and make visible a long-term move which has accelerated during the post WW2 period and may accelerate further.
} 
- As the "material conditions of information technology production", i.e. the industry and technologies producing computer-based systems;

- As "one of the universal metaphors of contemporary life";

- As a "materiality of representation".

Like Dourish and Mazmanian (2013), our interest is in the sociomaterial aspects of information. More specifically we are interested in exploring the last two aspects above; they concern metaphors and representations, whereas the others address digital goods and their creation. Information has become a universal metaphor and this implies "an informational approach to seeing and understanding the world that diminishes some forms of knowledge and authorizes others" (Dourish and Mazmanian 2013, 99). Our second concern is the representational consequences of the materiality of information. "The particular forms that information takes (...) shape the questions that can be easily asked of it, the kind of manipulations and analyses it supports, and how it can be used to understand the world" (100). Indeed:

"Metaphor and representation suggest potential lines of action, ways of engaging with the world, and techniques for understanding and approaching both the known and unknown in physical, social and virtual environments. These information forms shape how we interpret and imagine broader surroundings." (Dourish and Mazmanian 2013, 100).

To explore these two aspects further, our argument will be historical in nature. Its aim is to bring to the fore long-term movements to situate the historical status of information and its place in social dynamics in organisations, by concentrating on relationships between the materiality of information and modes of organising. We hope to bring information and not just technological artefacts as an object of debate on the sociomateriality of organisations and organised collective activity (Orlikowski 2007; Leonardi 2011; Logan, 2012; de Vaujany and Mitev 2013).

Today's information is materialised more than it is material. It is a constant flow that is simultaneously and recursively materialised through media, most of which now global. We suggest that this movement is grounded in a substantial conceptual revolution that we see as symbolised by the Macy conferences. Drawing on Heims (1991), Dupuy (1994), Hayles (1999) and Wyner (1974) who consider them as an historical turn, we examine Macy's (re)definition of information and meaning and the conception of technologies rooted into this definition, as they become a "medium" (McLuhan 1964).

After presenting the three disruptions in organising we have identified above, we will revisit the key conceptual apparatus stemming from the Macy conferences: information, information value and information technology (computers).We will then draw on iconographical (in particular [Baschet 2008]) and semiotic (in particular [Peirce 1978]) theoretical approaches to offer a critique of this apparatus and the implications for organising. 
We will show that the three major disruptions in organising are grounded in a new semiosis ${ }^{3}$ which emerged implicitly and unobtrusively over a longue durée.

\section{From information to meaning: an exploration of the matter of information from the Macy conferences}

\section{Metaphors of information and organising: three disruptions in post-Macy societies}

We will first come back to Dourish and Mazmanian (2013)'s invitation to explore the material underpinnings of 'information'. Following from Hayles (1999) and Bauman and Lyon (2013), we identify the following key trends in contemporary 'semiosis'.

We now live in a world where information is everywhere, abundant, omnipresent, and the scarce resource has become the attention capacity of organisational members (Simon 1990; Wright 2007; Day 2008; Black, Muddiman, and Plant, 2007; Ibekwe-SanJuan and Dousa 2014). The attention capacity of individual and organisational members is now crucial (Simon 1990), and so is their reflexivity as "invisible" technologies (Berry 1983) spread.

Information as a 'process' is now both a movement and an immersion within an abundant circulating 'liquid'. One does not move any longer towards information. One does not interact with information media, one "lives in" information (Serres 2012). Like the teenagers described by Serres, people are now inside information technological structures, regardless of when, where or whether they use them. In schools, even if they do not interact directly with it, pupils develop Facebook-like social ties and interactions. The 'process' of information is becoming a "screen-image" (Baschet 2008): it is making sense through appearing on the screen at the same time as in people's minds; it is becoming less meaningful ex ante. ${ }^{4}$ Additionally, to sustain this, a vast system of consultants, editors, publishers, etc. relentlessly produces information and artefacts. Organisations are inundated and this feeds their constant search for innovation and consumption of over-abundant information, probably to the detriment of developing their own organisational reflexivity.

This information-centred world is leading to three interrelated disruptions in organising (see Figure 1 below): new modes of performativity and surveillance which are difficult to comprehend and deal with (Bauman and Lyon 2013) (Disruption 1); a transformation of meaning and knowledge in collective activity (Hayles 1999) (Disruption 2); and a disembodied semiosis (Hayles 1999) (Disruption 3).

\footnotetext{
${ }^{3}$ Semiosis relates to any form of activity or process that involves signs (Peirce 1978), including the production of meaning.

${ }^{4}$ Furthermore, the design of new media such as wearable sensors inside clothes through which body movements provide information and sometimes energy to the medium, or artefacts enabling geo-localisation, tactile navigation, anthropomorphised interactions, etc., creates "screen-images" which encounter an individual's body.
} 


\section{FIGURE 1 ABOUT HERE \\ Three self-reinforcing tendencies}

The first disruption is affecting the performative nature of discursive practices. The post WW2 period led to tools and concepts now widely used in organisations ${ }^{5}$ to provide employees and customers with cognitive artefacts in order to process huge amounts of 'information': "Post-war design and communication sciences increasingly viewed the world as data filled, necessitating new tactics of management to which observers had to be trained and the mind reconceived" (Halpern 2014). Through the use of Google ${ }^{\mathrm{TM}}$ for instance, employees, customers and citizens increasingly rely on external knowledge. This reminds us of the image of the decapitated Saint Denis, walking while holding his head in his hands. Cognition is 'at hand', but in an external relation to their embodied experience (Serres 2012). Algorithms and logical automata are enmeshed into routines and this opens the door to new forms of performativity. The selection and structure of information, e.g. appearing or not on the first page of Google results or among the right pages of Facebook, is subtly enmeshed into a sociomaterial practice (Orlikowski 2007). Beyond the presence or use of IT, people now 'think' Google or Facebook at work and in their everyday lives. Tools designed to represent the state of knowledge or to manage social ties have a new performative effect. Access to this performative process (and its "felicity conditions", see [Austin 1962]) is more complex than that of a book or pre-Macy artefacts. It is also difficult to access or modify the infrastructure of their supporting global networks (Halpern 2013); that requires vast amounts of expertise and resources and is paradoxical in what is often called the world of 'end-user computing'.

The growth of unobtrusive "invisible technologies" (Berry 1983) has created sophisticated modes of performativity which support the design, management and activities of organisations. Algorithms and automata are spreading through global infrastructures which delineate which information matters and how to structure and access it, and support the "outsourcing of cognition" (Serres 2012). A monopoly of global digital infrastructures is beginning to replace a monopoly of access to information (in Western countries at least). By contrast, in the Middle Ages a monopoly of access through concretised information (scriptoria) was exerted by the Catholic Church and power laid in the skills and rights required to access this information both materially and cognitively (Barbier 2000). Digital information is becoming over-abundant (see the issue of extracting meaning from 'big data' see, e.g., [Bizer et al. 2012]), and power lies in the control of its social, material and cognitive infrastructures, which structure meaning, in particular to social and relational information (Galloway 2004; Bauman and Lyon 2013). Google ${ }^{\mathrm{TM}}$ and Facebook ${ }^{\mathrm{TM}}$ are some of the best examples of this change.

\footnotetext{
${ }^{5}$ Organisations are themselves represented, visualised and performed as 'entities', for instance with logos, organisational charts, rules and business processes, standards, targets, budgets, dashboards, material and immaterial spaces...
} 
In this "liquid world" (Bauman 2000) organisational practices do not necessarily exist in space-times with prior meaning or with a solid pre-existence (Bauman and Lyon 2013). Organised collective activity gets information from multiple media, which have a performative effect on meaning. This makes organisations more liquid, virtual, distributed and immaterial. Their structural physical aspects matter less than their collective activity: they can 'de-territorialise' by becoming a flow, which is constantly reshaped and re-materialised through local frames - thereby making themselves meaningful in the Shannonian sense of the term (i.e. a signal). In a liquid world, there even seems to be a risk for those organisations that have a long-term and material inscription into a territory (Bauman 2000).

Furthermore, with the second disruption, the emergence of an information-centred world implies a transformation of meaning for collective activity. Knowing is increasingly becoming disembodied (Hayles 1999; Bauman and Lyon 2013). It takes place away from familiar "corporeal frameworks"6 (Merleau-Ponty 1945/2004), rendering cognition more 'social' than 'human'. People are probably 'closer' than ever to each other; the social world is imbricated into material infrastructures such as electronic social networks; but humans are becoming further away from themselves and from true encounters with others. 'Rationality' more than 'passion' or 'embodiment' is part of the expectations of designers and managers of contemporary organisations. Perception and cognition are being redefined as "analogous to a communication channel and the observer reconceived as both self-referential and networked" (Halpern 2014). But sense-making is far from being a pure mental activity. Emotions and experience are central in meaning (Hayles 1999).Therefore outsourcing individual and collective cognition (Serres 2012) progressively affects both meaning and collective knowledge.

Paradoxically, digital over-abundance implies that more information is available to organisational members and becoming potentially meaningful (Barthes 1967; Eco 1979). Information is no longer a relationship that leads to a universal experience and is becoming a medium, a sign. Over the course of the 20th century the emergence of managerialist ideologies has often been combined with the use of ICTs and organisations are becoming spaces that manage digital media and signs. Strangely, if information has no matter or body in itself (Hayles 1999; Bauman and Lyon 2013), bodies, attitudes, intonations, behaviours, etc. become potentially meaningful information. Managers are becoming "screen-images" themselves. Managerial discourses often include information about organisational culture, vision, representations, identities, codes and images. The symbolic implications of this conceptualisation of information for organisations are important. This is what Feldman and March (1981) observed about the use of information:

"From a classical decision-theory point of view, information is gathered and used because it helps make a choice. (...) Observations of organizations are not easy to reconcile with such a picture. Individuals and organizations invest in information and information systems, but their investments do not seem to make decision-theory sense. Organizational participants seem to find value in

\footnotetext{
${ }^{6}$ i.e. the body assemblages as experienced by an individual through everyday activities.
} 
information that has no great relevance. They gather information and do not use it. They ask for reports and do not read them. They act first and receive requested information later" (182).

Their analysis is entirely based on information as an immaterial flow. Material aspects such as physical bodies and embodied experiences, and physical media that relay information and its materialisation are invisible and do not play any part in describing how information is used to ground and legitimate decisions for organisations.

Organisations and their modalities of problem-solving through information are generating problems for society at large such as: transformation and possible loss of meaning and of knowledge, through cognitive overload and equivocality (see [Weick 1990]), liquidity of society (Bauman 2000), duplication and waste of resources (see [Teulier and Lorino 2005]). New tools are constantly created and expected to process information in more relevant ways and enable better decisions. Experts, leaders, project managers are on the deck, while people in touch with everyday practices, employees, customers and citizens, are in the machine room. This "representationism", i.e. a focus on mental representations on the deck, disconnected from experience and collective activity in the machine room (Teulier and Lorino 2005; Lorino, Tricard, and Clot 2011) makes development of collective knowledge difficult.

Finally and relatedly, the post WW2 period opened the way to a disembodied semiosis (our third disruption), which is probably part of a long historical movement. The disjunction between mental activities and bodies or experience is indeed a long-term philosophical issue (Franchi and Güzeldere 2005; Mingers 2001; Mingers and Standing 2014). It is a major part of Western philosophies, e.g. with Descartes (1644/1988) and his well-known opus Les passions de l'âme. Articles XXXVIII ("Examples of body movements which accompany passions but do not depend on the mind") and XXXIX ("How the same issue can provoke different passions in different men") emphasise a major dichotomy between the body and the mind (Hayles 1999; Mingers 2001; Mingers and Standing 2014; Franchi and Güzeldere 2005). This has strong phenomenological implications. For the philosopher Alain (1928), happiness implies a connection between mental activities and the body, a mental process embedded in a here and now. The disembodiment, related to what we present here as a contemporary 'semiosis', makes this connection harder and harder. Beyond happiness, the integrity of the body is also becoming problematic in our digital world:

"More and more, bodies are in an ugly but apt world 'informatized'. In numerous surveillance situations, bodies are reduced to data, perhaps most obviously through the use of biometrics at borders. (...) One cannot but conclude that information about that body is being treated as if it were conclusive in determining the identity of the person. If the distinction is maintained, then one might worry about whether or not the fingerprint or iris scan adequately enrolls the person in the system, while ignoring what Irma van der Ploeg calls 'body integrity'. In condensed form, this is the story of how disembodied information ends up critically affecting the life chances of flesh-andblood migrants, asylum-seekers and the like.” (Bauman and Lyon 2013, 134). 
The cognitive, physical and social connectedness resulting from the tools designed after the Macy conferences are making us potentially closer than ever to each other... but maybe further from ourselves than ever (Turkle 2012). The next section retraces the history of the Macy conferences, seen as a significant event in this long-term evolution, to understand how we got here.

\section{The Macy conferences: back to the roots of the problem?}

Without a doubt, the Macy conferences were a major event in the sciences at large, primarily in the fields of cybernetics, computer science, and the information sciences (Heims 1991; Dupuy 1994; Hayles $1999^{7}$ ). While at the time they were an opportunity to develop new concepts or new theories per se, they were an amazing space for the interdisciplinary sharing, legitimating and reinforcing of unique ideas concerning human thought, its development, control, and conversely, emancipation. Organised between 1946 and 1953 by the Macy Foundation at the Beekman Hotel in New York City, these conferences consisted of meetings between leading scientists such as Mead, Von Neumann, Shannon, Bateson, Wiener, Parsons and many others (see Appendices 1 \& 2).

They key aim was to understand the human mind, and think the possibilities of its emancipation. The event took place in the immediate post-WW2 period, and was permeated by the will to protect humanity from this nightmare reoccurring (Heims 1991). Promoting a new rationality, less passionate, more mental, was a key approach. To do this, Macy produced a coherent new vision of information related to disembodied and intentional signs and moved one step further in the design of new logical automata ${ }^{8}$ likely to process this new type of information. In the emerging Cold War period, the Macy conferences were also infused with a dread of the possibility of a new global war, therefore requiring more control, in line with the cybernetic movement (Heims 1991). Macy was at the core of a new project of society ${ }^{9}$ more than a project for cognition, organisations or administration which developed later in the field of administrative sciences with Herbert Simon's information processing paradigm (see e.g. [Newell and Simon 1972]). This societal project was at the heart of the "mentalist"

\footnotetext{
${ }^{7}$ Most elements used in this section are based on these three key (rare) references about the event. Heims provides an historical account of the event, putting it into the perspective of WW2 and the Cold War; Dupuy focuses on the cognitive and epistemological implications of the conference; whereas Hayles emphasises the literary stance and underlying metaphors conveyed by Macy. We also used some archives available on the Cybernetic Society website (http://www.asc-cybernetics.org/foundations/history/MacySummary.htm), in particular information about each conference and their proceedings.

${ }^{8}$ First designed as an analogy to the human mind, whereas later the human mind was thought about as an electronic brain (Dupuy 1994). Another paradox? In any case, this inversion favoured the legitimate structuring of human thought and experience through the new logical automata (all the more human-compatible as they were supposed to be inspired by the human way of thinking).

${ }^{9}$ See also Pickering (2002) who analyses cybernetics as pursuing scientific, technological but also artistic, organizational, political and spiritual worldly projects.
} 
computational paradigm denounced by Putnam $(1973,1979)$ or the "representationist" project criticized by Merleau-Ponty (1945/2004) and more recently, Lorino, Tricard and Clot (2011).

In this section, we will particularly focus on semiosis and the conception of information as epitomised by Macy. Following Hayles (1999), we will deal chiefly with (1) their definition of information and their construction of meaning and (2) their conception and design of technological architectures rooted into this conceptualisation (technologies become a medium), for which the Macy conferences should be considered as an historical turn (Wyner 1974; Hayles 1999).

Firstly, Shannon and Weaver legitimated the concept of information with a new theory (Le Moigne 1990; Gleick 2012; Ibekwe-SanJuan and Dousa 2014). It is related to the value of a piece of information and the degree of improbability of its occurrence $(\mathrm{H})$. To use two famous examples (see Le Moigne 1990), guessing the results of flipping a coin (1/2) gives less information than displaying the location of a pawn on a chessboard (1/64). Building on Hartley (1928), this is the key idea that Shannon put forward with his famous formula (see Figure 2).

\section{FIGURE 2 ABOUT HERE Shannon's formula $(1948,380)$}

The Macy conferences also enabled the development of a logic of transmission of information, related to the occurrence of a signal. More specifically, they proposed the concept that if something is circulating or can circulate between a sender and a receiver, the manager of the channel must minimise noise (a key technical and cognitive stake to produce an objective representation for the receiver) and facilitate the encoding and decoding of information (see Figure 3).

\section{FIGURE 3 ABOUT HERE} The classic process of information transmission (Shannon 1948)

The implications of these new notions were radical. We have to focus on the idea of a channel; after the invention of electricity, new infrastructures emerged during the $20^{\text {th }}$ century which became seen as conveying information ${ }^{10}$, and a transmission medium key in the decoding process, which can embody, materialise and perform information. Whether or not it is meaningful, the valorisation of this medium is central. Indeed, "information is defined independently of the medium of its instantiation", it is "a probability function with no dimension, no materiality, and no necessary function with meaning. It is a pattern, not a presence.” (Logan 2012, 84).

\footnotetext{
${ }^{10}$ In addition, the Macy conferences will be an opportunity to discuss the meaning of information compared to that of energy and entropy (Hayles 1999).
} 
Most of all, the Macy conferences were a unique opportunity for legitimating a certain vision of the human mind and for envisaging a technological artefact that became central to our societies and information economies: the computer. McCulloch and Pitts (1943), the inventors of formal neural networks, as well as Von Neumann (1945/1993) with his proposals concerning logical automata, were at the heart of the scientific debates during the conferences. The human mind is understood as a set of neurons using binary logic, making it simpler to model computer technology as a logical system expected to convey information. It facilitates a process of design in which Macy is one step amongst others, i.e. the development of computers and of computer science. If the human mind is a logical system, it can be transposed into a numerical machine, as far as this machine is able in turn to reproduce a binary logic.

This principle is at the heart of modern computers (Godfrey and Hendry 1993), and more generally, what is called the "Von Neumann's architecture" (see Figure 4).

\section{FIGURE 4 ABOUT HERE Von Neuman's architecture (adapted from Von Neuman 1945/1993)}

The key ideas are: a memory stores both data and programmes; a unit of control arranges the sequence of data to be processed (i.e. signals circulating inside the system); a processing unit activates them; and an input-output system enables human interactions with the machine.

This architecture is fully coherent with the broader vision of information that was developed during the Macy conferences, in which information is a flow that requires processing and computation. The resulting modern computer is clearly a tool dedicated to the computation of information, more than an analogue calculator. By reproducing the logical system of the human mind as was envisaged in the 1940s, it simulates information processing. Ultimately, output systems will 'perform' information, with electric signals, cards, or more recently, computer-screens. This last move is crucial as it is the locus of information "occurrence" (as described by the Shannon's vision of the value of information as "occurring" at the representational level).

With Macy, a key metaphor of information emerged, putting it at the core of social life:

"Directing attention through informational metaphors is pervasive in everyday settings as well, where information flows, models of data processing, and computational command-and-control serve as cultural logics for understanding and narrating the world around us, whether psychological experience (how we 'store' and 'process' events), commercial activity (viral advertising draws more on the logic of computer viruses than it does on biological ones), or bed-springs ("sense and response coils", in 
the parlance of one American television metaphor), they begin to have material consequences as those elements of the world that do not easily fit into the metaphor (emotion, for instance) are either reframed or become invisible in public discourse." (Dourish and Mazmanian 2013, 99).

Interestingly, the three conceptual pieces we emphasise here (theory of information, theory of the value of information, theory of new cognitive artefacts) all rely on an important philosophy which will be (and still is according to us) at the core of management and organisation thought, in particular Newell and Simon (1972)'s further formalisations. It is what Lorino, Tricard and Clot $(2011,771)$ call a "representationist" philosophy. Here, "representing" means paralleling the objects of the world with "physical" symbols which can be manipulated according to logical rules and become "computable" symbols. The symbols (information), their value (grounded both in their occurrence and possession) and the tools (both human and computer-based, according to a strange symmetry) likely to process them, were at the core of Macy and its cybernetic debates.

Where is meaning in this process? How are bodies and the materiality of computer systems incorporated into this conceptualisation? This debate also took place during the Macy conferences through presentations and comments by Bavelas, MacKay or Bateson and show that meaning became absent (see [Dupuy 1994; Hayles 1999]).

MacKay (1969) realised the consequences of such a stance, which neglects transmission as a relationship between a signal and a set of possible answers from the logical perspective of a receiver. With regards to Shannon's formal and logical conceptualisation of information, MacKay insisted on the organising power of information ${ }^{11}$, the logics at stake between senders and receivers and receivers' dispositions towards interactions, or their "state of readiness":

"It looks as if the meaning of a message can be defined very simply as its selective function on the range of the recipient's states of conditional readiness for goal-directed activity; so that the meaning of a message to you is its selective function on the range of your states of conditional readiness." (MacKay 1969, 24).

Nonetheless, his project remained to objectify the dispositional space or mindset of the receiver:

"Let us do so by asking in more general operational terms what difference it makes when I gain information. Fundamentally it implies that in some circumstances or other my expectations will be different. I am now conditionally ready to react differently. The reactions potentially affected may be internal or external." (MacKay 1969, 60).

\footnotetext{
11 In terms of the activities related to the exchange: "When is a question meaningless? Some people would argue that a question is meaningless unless one has some physical way of verifying the answer to it (...). At the other extreme are those who would admit any question to be meaningful if people in fact ask it." (MacKay 1969, 3637).
} 
This is still inscribed in a logical system and not in the context of a body, a mood, a perception, a socialisation, a biological brain or more generally a 'knowing'. Information has no body per se:

"By picturing an item of information as a kind of tool that operates upon the recipient's internal state of conditional readiness, we can conveniently define its meaning on the one hand, and its information-content (in various senses) on the other." (MacKay 1969, 19)

The Macy conferences were clearly a meeting of complementary thoughts for Shannon and Weaver. Bavelas focused on 'meta' communication processes and Bateson on a more epistemological posture or a process of knowing and differentiation. However, in the context of the Macy conferences (and its leaders), they stopped short of constituting an alternative theory of information (a semantic theory) to that of Shannon and Weaver (Hayles 1999). During the debates, the key leaders (and their followers after the Macy conferences themselves) favoured a design-oriented, acontextual, disembodied, non-evolutionary vision of sense-making processes and information. Indeed, these themes are inscribed in another historical logic coherent with the time period of the early 1940s. New technological tools developed by the US military were appearing on the horizon for society and organisations and from that moment on, transmission and flow became crucial in terms of producing meaning.

Reminders and warnings about the emerging Macy epistemological posture and its implications have been many. Shannon himself (an electrical engineer) insisted on the engineering posture that underlies his work. His aim was to model processes of information transmissions as signals. As he stated in his seminal publication (Shannon 1948, 379):

"Semantic aspects of communication are irrelevant to the engineering problem. The significant aspect is that the actual message is one selected from a set of possible messages. The system must be designed to operate for each possible selection, not just the one which will actually be chosen since this is unknown at the time of design."

In the context of the Macy debates, as well as in most contemporary debates, this warning has been largely forgotten. Most of all, no clear integrated alternative approach emerged in the time and space of the Macy conferences (participants remained divided, even in their criticism, see Bateson's proposal in 1973 [Bateson 1973]). Shannon's posture similar to what Wiener drew from it in the field of cybernetics (Hayles 1999) - crystallised a new relationship with information that was already looming in the 1940s. Thus, for Shannon, "defining information as a probability function was a strategic choice that enabled him to bracket semantics. He did not want to get involved in having to consider the receiver's mindset as part of the communication system" (Hayles 1999, 54).

Hayles $(1999,2)$ further analyses it as a political vision of individuals and their relationship with information. She describes it as 'posthuman' characterised by the following assumptions:

"First, the posthuman view privileges informational pattern over material instantiation, so that embodiment in a biological substrate is seen as an accident of history rather 
than an inevitability of life. Second, the posthuman view considers consciousness, regarded as the seat of human identity in the Western tradition long before Descartes thought he was a mind thinking, as an epiphenomenon, as an evolutionary upstart trying to claim that it is the all show when actually it is only a minor sideshow. Third, the posthuman view thinks of the body as the original prosthesis we all learn to manipulate, so that extending or replacing the body with other prostheses becomes a continuation of a process that began before we were born. Fourth, and more important, by these and other means, the posthuman view configures the human being so that it can be seamlessly articulated by intelligent machines. In the posthuman, there are no essential differences or absolute demarcations between bodily existence and computer simulation, cybernetic mechanisms and biological organism, robot teleology and human goals."

Hayles $(1999,51)$ underlines that "the triumph of information over materiality was a major theme at the first Macy conference. Von Neumann and Wiener led the way by making clear that the important entity in the man-machine equation was information, not energy." The body, the materiality of signs and their materialisation remained at the door of the Beekman Hotel until the end of the Macy conferences in 1953.

Macy delivered the vision at the core of Western philosophies, e.g. Cartesianism (Descartes 1644/1988). In the post-WW2 context, people wanted to produce a new world where passions and miscalculating would not re-occur (Heims 1991; Breton 1990; Hayles 1999; Keller 2004). Macy's cybernetic conceptual apparatus focused on self-regulatory systems, control, feedback loops, computation of signals (Bauman and Lyon 2013) and most of all the 'electronic brain' (Hayles 1999). This metaphor is important and seminal (Dupuy 1994). McCulloch, Pitts, and Von Neumann largely produced an artefact analogical to what was perceived as the functioning of the human brain (on the basis of several false assumptions, see [Changeux 1996]). This could also be described as a vast "surveillance assemblage" (Haggerty and Ericson 2000) or "moral delegation" (Latour 1987; de Mul 2009; Debary and Gabel 2010). Macy is also the product of an historical context, made both of the traumatism of WW2 and the increasing fear of the Cold War (Heims 1991; Breton 1990).

The computer brain is expected to lead society to a better state (Heims 1991; Hayles 1999). Beyond this, there is probably a very old imaginary which drives designers of artefacts enthused by rationalist philosophy. It dates back to theology itself. Breton (1990) reminds us of the importance of the Golem in Jewish mythology and sees it as one of the funding myths of computational artefacts:

"A Golem is (...) a humanoid made by man from clay and water, with incantations and spells. It is powerful. It grows a little more powerful every day. It will follow orders, do your work and protect you from the ever threatening enemy" (Collins and Pinch 1998, 2).

It has no blood, no embodiment, no life, no passion (Breton 1990; Collins and Pinch 1998). Clearly, this is a posthumanist move (Hayles 1999). More largely, the electronic brain and the digital move are part of a representationist philosophy emerging from the $17^{\text {th }}$ century onwards. With Descartes and Pascal, the mind has a profound ontology. And even though 
most scientists and people of the Enlightenment and post-Enlightenment period "have never been modern" according to Latour (2012), it seems that the Macy community was truly modern in that sense.

To grasp the originality and substance of the Macy shift, we will now put it into perspective with a historical comparison. We deliberately chose a very different time and space in order to emphasise the changes represented by Macy's semiosis and "screen-image" iconography. We will contrast it with an earlier semiosis and iconography prevalent till the late Middle Ages that we identify as "object-image". Our intention is to accentuate differences through this historical example and we are aware that these differences are probably less pronounced than we present them here. The next section very briefly outlines this historical illustration, therefore without fully exploring its social, cultural and symbolic systems of meaning, and draws on some accounts and analyses by medieval historians, particularly Baschet (2008).

\section{An iconographical and semiotic analysis of the Macy-related disruptions}

\section{Object versus screen-images: iconographical analysis to deconstruct the post-Macy era}

The construction of meaning in contemporary societies and organisations appears as a natural phenomenon. We consult information with our smartphones and tablets, we work with laptops, watch television, and read books with standardised formats. Our bodies, postures, intonations and clothing are the object of reflexive analysis, making it possible to extrapolate their hidden meanings. Why should all of this be put into a historical context? In order to answer these questions, we invite readers to take a trip back in time. We will critically appraise the modes of signification crystallised by the Macy conferences by considering the constructing of meaning in the Middle Ages, in particular from an iconographic perspective (de Vaujany 2012).

From an informational perspective, the Middle Ages were a material world. If information is etymologically a "shaping' ("mise en forme" in French [de Vaujany 2012]), this process had strong material underpinnings. During this period, according to Baschet (2008), icons, statues, buildings, bodies and even books were "object-images". Their meaning was the product of a matter, a place, a time of a ritualised practice (a Mass or a pilgrimage), which together and in a relational way converged towards a message. Each one was not expected to provide a unique experience, but rather to signify something universal.

It is important to recall that the Middle Ages consisted of a set of fragmented territories, an ensemble of local, autarkic societies, mainly oral, closed, where ways and means of transportation were quite limited and between which circulated (very slowly) a limited set of information (Verdon 2010). The temporal orientation was religious and 
eschatological. The rare artefacts (beyond the functional ones rooted in everyday life) that people encountered were often inscribed in a religious semantic system.

The iconography, images and their significance during the Middle Ages can be considered as "object-images". As Baschet $(2008,11)$ reminds us, before the $11^{\text {th }}$ century:

"One placed in churches only a mere cross (signumcrucis), we then slowly move to a tridimensional representation of the crucified (imago crucifixi). The first cultural statues also appear, like the Virgin with the Child of Clermont's cathedral (around 984) or that of Sainte Foy at Conques. Totally novel and unreleased at that time, such objects had to overcome much reluctance to construct their legitimacy, namely through the use of relics they contained or through narratives of miracles which would be related to them".

The materiality of icons, triptychs, and statues was fundamental in the processes of creating meaning during this period. The matter, place in space and time of religious rituals created meaning. Images were not (yet) a flow that would be materialised and lead to meaning through the use of a specific transmission medium. Meaning was inscribed into a physical, embodied, ritual relationship. Thus, "instead of the conjunction of two elements partially external to each other, image and medium, one attempted to conceive object-images as a whole, taking meaning through the relationships which are involved around them" (Baschet 2008, 51). Furthermore, medieval iconography semantics does not oppose texts (written) and images (drawn). Books and the pages that they contain are pictura; the same verb (pingere) can relate to the activity of tracing letters or that of drawing an image.

The Chartres Cathedral, which is eight centuries old (Doré and Pansard 2012; Burckhardt and James 2012), represents this well. It is a complex object-image filled with other object-images. The entire building was intended to be experienced during religious rituals, specifically during Mass or pilgrimages. Pilgrims could move from the North portal (related to the Old Testament) to the South portal (focused on the New Testament); the scenes in the cathedral logically followed this theological perspective. The place, matter, and succession of statues, spaces, stained glasses, the time of encounter and the spatial practice at stake (a walk during a procession, a prayer, a specific act during a liturgy, etc.) were all meaningful. The entire set constituted a complex semantic system (Doré and Pansard 2012; Burckhardt and James 2012) that in turn became an embodied experience. While today each tourist leaves the place with his or her personal experience of the cathedral, during the Middle Ages pilgrims followed an order in which to experience a path and an emotion expected to be "universal". Furthermore, while contemporary visitors may find the place intriguing or wonderful, for medieval people the cathedral was simply meaningful. The building's matter did not contain a specific meaning, nor did it convey or transmit one; rather the choice, location, and time of encounter with artefacts had a meaning per se (Baschet 2008).

More than any other object, one located at the entrance of the Cathedral illustrates our message: the famous labyrinth (see Figure 5). 


\section{FIGURE 5 ABOUT HERE The labyrinth of the Chartres Cathedral (source: authors).}

This image-object was often present in Gothic Cathedrals. In France, only two remain visible at the Chartres and Amiens cathedrals.

At Chartres, the pilgrim coming into this symbolic space is destined to live a threestep experience (over the 261.5 metres of the labyrinth!) which was a way to do the Jerusalem or Compostela pilgrimage (Attali 1996). Firstly, he or she will think that the way to the centre will be easy. Then, it may seem that the path moves him/her more and more towards and around the extremities of the labyrinth. A feeling of being lost sets in. Then, as the pilgrim becomes desperate, his/her path leads to the centre. One must imagine a pilgrim, tired and exhausted. He/she has walked for days on end, entering a space whose dimensions were much more unusual than they may seem today. After a long tour over the labyrinth (often on the knees!), he/she will then begin a long path through the cathedral via the ritualistic encounter with this vast object-image.

In his analysis of image and iconography, Baschet (2008) suggests juxtaposing "object-images" with what he calls the "screen-images" of contemporary societies. The exercise will lead us back to the post-Macy conceptualisation of information.

Screen-images rely on an instantaneous iconography, a flow that materialises by means of a medium (a book with a standardised typeface or structure, the screen of a computer, an iPad, etc.). The time and space of the process of interpretation are not paramount in the creation of meaning, which is more related to the medium itself. A vast technical infrastructure made of standardised screens, corporate networks, Internet protocols, etc. and associated rules and routines of interaction, navigation and use enable individuals to implement these modes of sense-giving.

This infrastructure is essential. It includes all technical and cognitive means which enable the circulation of signs. It started emerging in the Western world in the $16^{\text {th }}$ and $17^{\text {th }}$ centuries through a standardised writing which more and more literate people could access without the need to understand palaeography (Febvre and Martin 1958; Bozzolo and Ornato 1983); it evolved in the $19^{\text {th }}$ and $20^{\text {th }}$ centuries into material paper-based media produced on a large scale and at a low cost (Breton 1990); and then, into electronically-based media and networks. All these elements constitute a vast infrastructure which enables the circulation and embodiment of screen-images in a more ephemeral and fluid way than the object-images of the Middle Ages.

Since the Macy conferences, information has become progressively more disembodied and a process more than matter (Hayles 1999; Logan 2012). While the time, mood, and place of use can of course influence interpretation of the news just read on an iPad in a nonritualised way (which does not exclude some routines), even without them the medium appears a priori as being meaningful in itself in the process of interpretation. 
Our contemporary context is markedly different from that of the Middle Ages. Information as a flow is now over-abundant, we do not have access to closed semantic systems such as those found at the Chartres Cathedral and we live in a different 'ontology' (see [Descola 2005]). Books are no longer objects or a status symbol akin to jewellery. The triangle offered by Peirce (1978) is relevant here, and may be so more today than when it was developed by the philosopher. The distinction between the representamen, the "object" and the "interpreting" (see Figure 6) is very contemporary and corresponds to the dissociation between the representing and the represented emphasised by the screen-imagery of the late $20^{\text {th }}$ century.

In the transition from objet to screen-images, one can position the rupture represented by the Macy conferences. Information can now be materialised, performed, transmitted and commoditised; it has a value related to its "liquefaction" i.e. the possibility to move and be meaningful from one context to another. Indeed, Shannon and Weaver's information theory makes it measurable (see Figure 2 above).

The next section explores the implications of this conceptual evolution of information and its materiality for collective activity and organising. What is at stake with information as a flow and a screen-image rather than an object-image to be encountered in a semantic system? Our historical perspective sheds light on several implications that will be summarised below. They relate this evolution to the emergence of an increasingly "liquid" world (Bauman 2000) and of modes of organising and surveillance in which information is ephemeral, mobile and global (Bauman and Lyon 2013). This is also related to the development of a generalised advanced modernity (see [Giddens 1991]) linked to the abundance of information and its performativity. All of this makes more urgent than ever a form of management that can restore some continuity, even if fragile, to organised collective activity.

\section{From iconographical to semiotic analysis: the sociomaterial underpinnings of contemporary semiosis in organizations}

According to Baschet (2008), semiosis appears as an historical construct. The semiosis of the Middle Ages as described through object-images is different from that of contemporary screen-images. We propose to use Peirce's theory of signs to analyse this further - although his conceptualization is modernist and does not really correspond to the medieval semiosis ${ }^{12}$. His main concepts are representamen, object and interpretant and are related in the following way (see Figure 6).

FIGURE 6 ABOUT HERE

Peirce's semiotic triangle (based on Mingers and Willcocks 2014, 55)

\footnotetext{
${ }^{12}$ Although the Latin etymology of 'sign' is the notion of 'miracle'...
} 
In the medieval semiosis of object-images, representamen and the object were more closely related. The vocabulary and development of the system of signs, with signs often uniquely instantiated, were closely associated, making Pierce's two concepts less adequate Peirce's modernist semiotics is probably more appropriate to analyse Western contemporary ontologies. In addition, the interpretant encountered artefacts in the context of ritualistic practices such as a pilgrimage or a Mass. The dynamic interpretant was more predictable: laypeople encountered systems of signs designed in familiar and shared contexts. With screen-images and the post-Macy era, the distinctions between the three concepts in the triangle have become more clear-cut. Digital signs can be argued to be representamen, have become mass-produced and abundant (see our first section) and more distinct and distant from objects and interpretants.

Bearing in mind Macy's initial vision, it may seem paradoxical that its semiosis can also bring some ruptures between the personal, the social and the material ${ }^{13}$, three realms which interact, as suggested in a recent contribution by Mingers and Willcocks (2014).This is a very long-term movement, that we chose to explore here through the Macy conferences. These ruptures between the three realms relate to happiness and well-being more specifically. Indeed, "electronic mediation enables a further distancing between the actor and the outcome than could ever have been imagined in the pre-digital bureaucracy. But it also rests on a shriveled-up and scarcely recognizable notion of 'information' that has been pried free from the person" (Bauman and Lyon 2013, 134). Personal mental processes are more and more outsourced (Serres 2012) as individual cognition is being encapsulated in knowledge systems and retrieval delegated to search engines and social networks. Mental activities and the here and now of the individual body are being separated. The widespread use of screen-images and the necessity of constant connectedness and reactivity represent a continuous projection to an 'elsewhere' and an 'after' rather than the 'here and now'. This can lead to individual and collective frustration and heighten the risk of mental hyper-activity.

The famous Propos of the philosopher Alain (1928) brings interesting insights from an individual psychological perspective into this phenomenon. According to Alain: "The body (...) suffers through ideas and heals through action. Thinking is arduous and turbulent beyond just dealing with logical problems. And this additional turbulence is what leads to beautiful thoughts" (29). The construction of individual happiness requires overcoming one's moods in order to be fully in one's body and avoid the mental and emotional wandering and drifting caused by a world of hyperlinked screen-images. From a phenomenological perspective, it requires an action, an intentional, deliberate behaviour. Indeed:

"Reacting against moods is not an issue of intellectual judgment which is of limited help. It requires shifting one's attitude and adopting appropriate moves; indeed, our physical muscles are the only part of ourselves we truly control. Smiling or shrugging our shoulders are well-known reactions in tense situations. These easy movements quickly improve circulation within our inner organs" (37) and our general well-being.

\footnotetext{
${ }^{13}$ The personal world through the generation and interpretation of signs and messages; the material world in that signs are physically embodied; and the social world in that the connotive aspects of sign systems are social (Mingers and Willcocks 2014, 48).
} 
At a time when one questions the sociomateriality of our world, it is important to remember that our body is an essential social instrument, as expressed in the notion of "embodied" phenomenology in the philosophy of perception (see [Merleau-Ponty 1945/2004; Feyereisen and de Lannoy 1991; Pickering 2005]). For Alain (1928), the body is both the key space for the construction of individual happiness, and one of its worst enemies. Indeed, extreme action, in particular when it is dissolved into collective activity, is also that which departs the most from ethics: "in all men, action makes consciousness vanish" (105). For Alain, the most important thing remains the serene contemplation of a "horizon", a perspective which involves us recursively with ourselves. This exploration, which can be grounded into action, is a vast field of deliberate and careful associations, and not a compulsive or rootless drifting in cyberspaces. It is also and always an action which gives us back our own selves and our bodies in the material and symbolic context of this 'horizon'. Alain $(1928,123)$ states:

"Where will science lead us, as long as it is not too ambitious, wordy or impatient; as long as it distances us from books and brings us new horizons. It must therefore be about perception and travel. Discovering true relations through an object can lead to many others, and this move can lift our thoughts towards winds, clouds and planets. True knowledge cannot be reduced to little things right in front of our eyes; knowing is to understand how the smallest thing is related to the whole; no object possesses its own essence within itself, thus isolating us from ourselves; this is unhealthy for our minds and our eyes. Where our thoughts will rest in this universe, which is their domain, and will be in harmony with our bodily lives which are connected to all things. Look far into the horizon".

\section{From the how to the why of 'moral delegation': discussion on the new unobtrusive material underpinnings of information}

Our goal here was not to explore various theories of information (see, e.g., [McKinney and Yoos 2010]). Nor was it to explore scientific alternatives to Shannon's account of information. We invite readers interested in these issues to look at embodied cognition as conceptualized by Maturana (1978), Merleau-Ponty (1945/2004, 1969) or Varela, Thompson and Rosch (1991); or beyond body and individual cognition, more recent sociomaterial research by for instance Pickering (1995) and Orlikowski (2007). Our ambition was more to provide an historical and critical perspective on the notion of information as it stabilised in the post WW2 period. 
The Macy conferences are very interesting as a 'window' into, or a 'revealer' of, a long-term movement in which the emergence of a new semiosis and iconography appears to be associated with new moral and cognitive 'delegations' ${ }^{14}$.

Firstly, our historical comparison with the pilgrimages at the Chartres Cathedral in the Middle Ages, emphasises the emergence of a more disembodied and changing performative semiosis. With screen-based imageries, sense-making and signs are 'performed' differently. Information is becoming a constant flow among people embedded into a global infrastructure which Macy concepts and apparatus have made possible. In contrast to the Middle Ages, we are also moving from a 'monopoly of access' to a 'monopoly of infrastructure' (Galloway 2004). This situation can be problematic if our signs are more and dependent on these infrastructures, and if these infrastructures are controlled by a limited set of companies.

This creates a context in which cognitive and moral delegations are becoming entangled into a digital world which puts aside blood, passion, instincts and is intended to represent and compute faithfully, objectively, the symbols of our world. The recent cognitive delegation developed since WW2 and facilitated by the Macy conferences is inseparable from the moral delegation initiated by Western philosophers (e.g. [Descartes 1664/1988]) a long time ago.

Cognition is being increasingly outsourced and this has moral implications. Computer tools have become so anthropomorphised that cognitive routines are entangled into search engines and logical automata which affect what we know and how we know it. They simultaneously enable and constrain relations and associations. The intermingling of this recent cognitive delegation with a moral delegation which has long historical roots constitutes the core of the post-Macy paradox. It would probably be an unexpected outcome for most Macy participants.

Finally, beyond the question of the how, that is describing how the Macy cognitive delegation is entangled with an earlier moral delegation, we also see our work as pointing towards the question of the why of moral delegation. New normative assemblages pervade our lives today. Similarly to Latour's famous case studies (e.g. hotel keys or road speed-bumps), IT-based systems are becoming ubiquitous and pervasive and part of performative and ostensive routines (Feldman and Pentland 2003). How did we reach that point? What could be done to question, make explicit and re-humanise this contemporary semiosis? This would involve many social and organisational actors, from governmental and educational to human resource management and IT players.

\footnotetext{
${ }^{14}$ At this stage, we use the term 'delegation' more as a metaphor (see Dourish and Mazmanian 2013) than the concept of delegation as used in ANT (see, e.g., Ribes et al. 2013). Moral delegation corresponds to the expectation that a mere material artefact will convey a norm for social interactions, a regulation (de Vaujany et al. 2015). Cognitive delegation corresponds to the expectation that a material artefact will structure individual or collective modes of cognition. From an ANT viewpoint (Latour 2005), Macy could be described more as a longterm prescriptive assemblage, and an evolving network including first some academics, the US army, the electronic brain, diodes, tubes, the Nazi, the Soviet, to a more recent assemblage including consumers, major global companies, financial markets, major global states, terrorists, tactile systems, mobile systems, protocols and infrastructures.
} 
To conclude, we see both the how and why questions as interconnected from an ethical perspective, i.e. the values and principles which should guide individual and collective action. More than ever, we need to encourage a diversity of philosophical ontologies (see, e.g., [Descola 2005; Kelly 2014; de Vaujany 2015]). Of course it is important to be able to make sense of assemblages; but we argue here that is also important to disentangle human and non-human entities to reflect on ethical aspects. This requires a phenomenological posture likely to make sense of people's corporeal frameworks and their relationships with their mental and cognitive individual and organisational activities. This is what we tried to emphasise when drawing on Alain (1928) and his vision of embodied happiness.

'Information', as conceptualised from the Macy conferences, is at least as old as computer science, information science and management information systems but its organisational implications deserve to be explored from historical, semiotic and sociomaterial perspectives, the latter having so far mainly concentrated on information technologies rather than information and its effects on our well-being and happiness. This seems a particularly hot topic at a time when artefactual information is becoming intertwined with every individual or collective activity we can imagine.

\section{Acknowledgements}

\section{References}

Alain, E.C. 1928. Propos sur le bonheur. Paris: Éditions Gallimard.

Allen, D. and T.D. Wilson. 2003. "Information Overload: Context and Causes". The New Review of Information Behaviour Research 4(1): 31-44.

Attali, J. 1996. Chemins de sâgesse. Paris: Fayard.

Austin, J.L. 1962. How to do Things with Words. Cambridge, MA: Harvard University Press.

Barbier, F. 2000. Histoire du livre. Paris: A. Colin.

Barthes, R. 1967. Elements of Semiology. New York: Hill and Wang.

Baschet, J. 2008. L’Iconographie médiévale. Paris: Folio.

Bateson, G. 1973. "Form, Substance and Difference." In Steps to an Ecology of Mind, edited by G. Bateson, 423-440. London: Paladin.

Bauman, Z. 2000. Liquid Modernity. Cambridge: Polity.

Bauman, Z. and D. Lyon. 2013. Liquid Surveillance. Cambridge: Polity.

Berry, M. 1983. Une Technologie invisible : L'impact des instruments de gestion sur l'évolution des systèmes humains. Paris : Centre de Recherche en Gestion de l'Ecole Polytechnique.

Bizer, C., P. Boncz, M.L. Brodie, and O. Erling. 2012. "The Meaningful Use of Big Data: Four Perspectives, Four Challenges. ACM SIGMOD Record 40(4): 56-60. 
Black, A., D. Muddiman, and H. Plant. 2007. The Early Information Society: Information Management in Britain before the Computer. Champaign: University of Illinois Press.

Boell, S. and D. Cecez-Kecmanovic. 2011. "Theorizing Information: From Signs to Sociomaterial Practices". Paper presented at the $22^{\text {nd }}$ Australasian Conference on Information Systems, Sydney, Australia, November 30- December 2.

Boisot, M.H. 1998. Knowledge Assets: Securing Competitive Advantage in the Information Economy: Securing Competitive Advantage in the Information Economy. Oxford: Oxford University Press.

Bozzolo, C. and E. Ornato. 1983. Pour une histoire du livre manuscrit au Moyen Âge. Trois essais de codicologie quantitative. Paris: Éditions du Centre National de la Recherche Scientifique.

Breton, P. 1990. La Tribu informatique. Paris: Métailié.

Burckhardt, T. and J. James. 2012. Chartres and the Birth of the Cathedral. Bloomington, IN: World Wisdom Books.

Case, G. 1997. Silence Descends: The End of the Information Age, Vancouver, BC: Arsenal Pulp Press.

Castells, M. 2000. End of Millennium: The Information Age: Economy, Society, and Culture. Vol 3. $2^{\text {nd }}$ ed. Malden: Blackwell.

Changeux, J.P. 2006. L’homme neuronal. Paris: Hachette literature.

Collins, H.M. and T. Pinch. 1998. The Golem: What you Should Know about Science. Cambridge: Cambridge University Press.

Crowston, K. and C. Østerlund. 2013. "The Socio-Materiality of Information-Documents and Work". Minitrack Introduction presented at the 46th Hawaii International Conference System Sciences, Grand Wailea, Maui, Hawaii, January 7-10.

Day, R.E. 2008. The Modern Invention of Information: Discourse, history, and power. Carbondale: Southern Illinois University Press.

Debary, O. and P. Gabel. 2010. "Seconde main et deuxième vie. Objets, souvenirs et photographies. Mélanges de la Casa de Velázquez.” Nouvelle Série (40-1): 123-142.

Descartes, R. 1664/1988. Les passions de l'âme. Paris: Librairie philosophique J. Virin.

Descola, P. 2005. Par-delà nature et culture. Paris: Gallimard.

De Mul, J. 2009. “Des machines morales.” Cités (3): 27-38.

de Vaujany, F.-X. 2012. "Une comparaison Moyen Age-période contemporaine sur le rapport à l'information dans l'action collective organisée", Cahier de Recherche de la Chaire Intelligence Economique et Stratégie des Organisations (IESO) 1.

de Vaujany, F.-X. 2015. "The 'ontological turn' of anthropology: implications for debates about sociomateriality." Paper presented at the Annual Conference of the European Group on Organization Studies (sub-theme 45: Materiality, Human agency and practice), Athens, 2-4 July. 
de Vaujany, F.-X. and N.N. Mitev. 2013. "Space in Organizations and Sociomateriality". In Materiality and Space: Organizations, Artefacts and Practices, edited by F.-X. de Vaujany and N. Mitev, 1-21. Basingstoke: Palgrave Macmillan.

de Vaujany, F.-X., N.N. Mitev, F.G. Lanzara and A. Mukherjee, eds. 2015. Materiality, Rules and Regulation: New Trends in Management and Organization Studies. Basingstoke: Palgrave Macmillan.

Doolin, B. and L. McLeod. 2012. "Sociomateriality and boundary objects in information systems development." European Journal of Information Systems 21(5): 570-586.

Doré, J. and M. Pansard. 2012. Chartres, la grâce d'une cathédrale. Paris: Editions Place des Victoires.

Dourish, P. and M. Mazmanian. 2013. "Media as Material: Information Representations as Material Foundations for Organization Practice." In How Matter Matters: Objects, Artifacts and Materiality in Organization Studies, edited by P. R. Carlile, D. Nicolini, A. Langley and H. Tsoukas (Series on Perspectives on Process Organization Studies), 92-118. Oxford: Oxford University Press.

Dupuy, J.-P. 1994. Aux origines des sciences cognitives, Paris: La Découverte. (Also published as On the Origins of Cognitive Science: The Mechanization of Mind. Cambridge MA: MIT Press, 2009).

Eco, U. 1979. A Theory of Semiotics. Bloomington: Indiana University Press.

Edmunds, A. and A. Morris. 2000. "The Problem of Information Overload in Business Organisations: A Review of the Literature." International Journal of Information Management 20(1):17-28.

Eppler, M J. and J. Mengis. 2004. "The Concept of Information Overload: A Review of Literature from Organization Science, Accounting, Marketing, MIS, and Related Disciplines." The Information Society 20(5): 325-344.

Febvre, L. and H .J. Martin. 1958. L'apparition du livre, Paris: Albin Michel (L'évolution de l'Humanité).

Feldman, M.S. and J.G. March. 1981. "Information in Organizations as Signal and Symbol." Administrative Science Quarterly 171-186.

Feldman, M.S. and B.T. Pentland. 2003. "Reconceptualizing Organizational Routines as a Source of Flexibility and Change.” Administrative Science Quarterly 48(1): 94-118.

Feyereisen, P. and J.D. de Lannoy. 1991. Gestures and Speech: Psychological Investigations. Paris: Editions de la Maison des Sciences de l'Homme.

Franchi, S. and G. Güzeldere. 2005. "Machinations of the Mind: Cybernetics and Artificial Intelligence from Automata to Cyborgs." In Mechanical Bodies, Computational Minds: Artificial Intelligence from Automata to Cyborgs, edited by Franchi, S. and G. Güzeldere, 145-149. Cambridge, MA: MIT Press.

Galloway, A.R. 2004. Protocol: How Control Exists after Decentralization. Cambridge, MA: MIT Press.

Giddens, A. 1991. Modernity and Self-Identity. Cambridge: Polity. 
Gleick, J. 2012. The Information. London: Fourth Estate.

Godfrey, M.D. and D.F. Hendry. 1993. "The Computer as Von Neumann Planned It.” IEEE Annals of the History of Computing 15(1): 11-21.

Haggerty, K.D. and R.V. Ericson. 2000. "The Surveillant Assemblage." The British Journal of Sociology 51(4): 605-622.

Halpern, O. 2013. "Nervous Infrastructures: Cybernetics, Design and Ubiquitous Computing." Paper presented at the History of Science Society Conference, (Panel: The History of Science and/as the History of Media). Boston, November 21-24.

Halpern, O. 2014. Beautiful Data: A History of Vision and Reason since 1945. Durham, NC: Duke University Press.

Hartley, R.V.L. 1928. “Transmission of Information.” The Bell System Technical Journal 535.

Hayles, N.K. 1999. How we became Posthuman: Virtual Bodies in Cybernetics, Literature, and Informatics. Chicago: University of Chicago Press.

Heims, S.J. 1991. The Cybernetics Group. Cambridge, MA: MIT Press.

Ibekwe-SanJuan, F. and T. Dousa. eds. 2014. Theories of Information, Communication and Knowledge. New York: Springer.

Keller, E. 2004. "Marrying the Premodern to the Postmodern: Computers and Organisms after World War II. Growing Explanations." Historical Perspectives on Recent Science, 181-198.

Kelly, J.D. 2014. "The Ontological Turn in French Philosophical Anthropology Ttheory." Journal of Ethnographic Theory 4 (1): 259-269

Lamoreaux, N R. and D.M.G. Raff. eds. 2007. Coordination and Information: Historical Perspectives on the Organization of Enterprise. Chicago, IL: University of Chicago Press.

Latour, B. 1987. Science in Action. Paris: Gallimard.

Latour, B. 2005. Reassembling the Social: An Introduction to Actor-Network Theory. Oxford: Oxford University Press.

Latour, B. 2012. We Have Never Been Modern. Cambridge, MA: Harvard University Press.

Leclerq, A., Carugati, A., Giangreco, A., da Cunha, J.V. and T.B. Jensen. 2009. "A Sociomaterial View of the Scaffolding of Work practices with Information Technology." Paper presented at the $30^{\text {th }}$ International Conference on Information Systems, Phoenix, Arizona, 5-18 December. Paper 197. http://aisel.aisnet.org/icis2009/197

Le Moigne, J. L. 1990. La modélisation des systèmes complexes. Paris: Dunod.

Leonardi, P.M. 2011. "When flexible Routines Meet Flexible Technologies: Affordance, Constraint and the Imbrication of Human and Material Agencies." MIS Quarterly 35(1): 147-167. 
Leonardi, P.M. 2012. "Materiality, Sociomateriality, and Socio-Technical Systems: What Do These Terms Mean? How Are They Different? Do We Need Them?' In Materiality and Organizing: Social Interaction in a Technological World, edited by P. M. Leonardi, B.A. Nardi and J. Kallinikos, 25-48. Oxford: Oxford University Press.

Leonardi, P.M. and S.R. Barley. 2008. "Materiality and Change: Challenges to Building Better Theory about Technology and Organizing." Information and Organization 18(3): 159-176.

Logan, R.K. 2012. "What is Information? Why is it Relativistic and What is its Relationship to Materiality, Meaning and Organization?" Information 3(1): 68-91.

Lorino, P., Tricard, B. and Y. Clot. 2011. "Research Methods for Non-Representational Approaches to Organizational Complexity: The Dialogical Mediated Inquiry." Organization Studies, 32(6): 769-801.

MacKay D.M. 1969. Information, Mechanisms and Meaning. Cambridge, MA: MIT Press.

McCulloch, W.S. and W. Pitts. 1943. "A Logical Calculus of the Ideas Immanent in Nervous Activity." The Bulletin of Mathematical Biophysics 5(4): 115-133.

McKinney, E. and Yoos, C. 2010. "Information about Information: A Taxonomy of Views," MIS Quarterly 34(2): 329-344.

McLuhan, M. 1964. Understanding Media, London: Routledge.

Maturana, H. 1978. "Biology of Language: The Epistemology of Reality." In Psychology and Biology of Language and Thought: Essays in Honour of Eric Lenneberg, edited by G. Millar and E. Lenneberg, 27-63. New York: Academic Press.

Mayer-Schönberger, V. 2011. Delete: The Virtue of Forgetting in the Digital Age. Princeton, NJ: Princeton University Press.

Merleau-Ponty, M. 1945/2004. Phénoménologie de la perception. Paris: Gallimard.

Merleau-Ponty, M. 1969. The Visible and the Invisible. Evanston, IL: Northwestern University Press.

Mingers, J. 2001. "Embodying Information Systems: The Contribution of Phenomenology." Information and Organization 11(2): 103-128.

Mingers, J. and C. Standing. 2014. What is Information Such That There Can Be Information Systems? Canterbury: University of Kent, Kent Business School Working Papers.

Mingers, J. \& L. Willcocks. 2014. “An Integrative Semiotic Framework for Information Systems: The Social, Personal and Material Worlds” Information and Organization 24(1): 48-70.

Newell, A. \& H.A. Simon. 1972. Human Problem Solving (Vol. 104, No. 9). Englewood Cliffs, NJ: Prentice-Hall.

Orlikowski, W.J. 2007. "Sociomaterial Practices: Exploring Technology at Work." Organization Studies 28(9): 1435-1448.

Peirce, C.S. 1978. Ecrits sur le signe. Paris: Editions du Seuil (see also Collected Papers of C.S. Peirce, Boston, MA: Harvard University Press, 1932-1954). 
Pickering, A. 2002. "Cybernetics and the Mangle: Ashby, Beer and Pask." Social Studies of Science 32(3): 413-437.

Pickering, A. 2005. "A Gallery of Monsters: Cybernetics and Self-Organisation, 1940-1970." In Mechanical Bodies, Computational Minds: Artificial Intelligence from Automata to Cyborgs, edited by Franchi, S. \& G. Güzeldere, 229-45. Cambridge, MA: MIT Press.

Pickering, A. 2010. The Cybernetic Brain: Sketches of another Future. Chicago: IL: University of Chicago Press.

Putnam, H. 1973. "Meaning and Reference." The Journal of Philosophy, 699-711.

Putnam, H. ed. 1979. Philosophical Papers: Mind, Language and Reality (Vol. 2). Cambridge : Cambridge University Press.

Rallet, A. \& F. Rochelandet 2011. "La régulation des données personnelles face au web relationnel: une voie sans issue?" Réseaux (3): 17-47.

Ribes, D., Jackson, S., Geiger, S., Burton, M. \& T. Finholt. 2013. "Artifacts that Organize: Delegation in the Distributed Organization." Information and Organization 23(1): 1-14.

Robertson, C. 2014. "You Lie! Identity, Paper and the Materiality of Information." The Communication Review 17: 69-90.

Rosenberg, D. 2003. "Early Modern Information Overload." Journal of the History of Ideas 64(1): 19 .

Serres, M. 2012. Petite poucette. Paris: Editions Le Pommier.

Shannon, C.E. 1948. "A Mathematical Theory of Communication.” The Bell System Technical Journal 27, 379.423, 623.656, July, October, 1948. (Reproduced in Shannon, C.E. 2001. "A Mathematical Theory of Communication." ACM SIGMOBILE Mobile Computing and Communications Review 5(1): 3-55 [available at http://dl.acm.org/citation.cfm?id=584093]

Simon, H.A. 1990. "Information Technologies and Organizations [Interview]." The Accounting Review 65: 658-667.

Simon, H.A. 1996. "Designing Organizations for an Information-Rich World." International Library of Critical Writings in Economics 70: 187-202.

Teulier, R., \& P. Lorino. 2005. "Entre connaissance et organisation: l'activité collective." In L'entreprise face au défi de la connaissance, edited by Colloque de Cerisy. Paris: La Découverte.

Turkle, S. 2012. Alone Together: why we Expect more from Technology and Less from Each Other. New York: Basic books.

Varela, F., Thompson, E. and E., Rosch. 1991. The Embodied Mind. Cambridge, MA: MIT Press.

Verdon, J. 2010. Information et désinformation au Moyen Age. Paris: Editions Perrin.

Von Neumann, J. 1945/1993. "First Draft of a Report on the EDVAC." IEEE Annals of the History of Computing 15(4): 27-75.

Webster, F. 2007. Theories of the Information Society. Abingdon: Routledge. 
Weick, K. E. 1990. “Technology as Equivoque: Sensemaking in New Technologies.” In Technology and Organizations, edited by P.S. Goodman and L.S. Sproull, 1-44. (The Jossey-Bass Management Series). San Francisco, CA: Jossey-Bass.

Wright, A. 2007. Glut: Mastering Information through the Ages. Ithaca, NY: Cornell University Press.

Wyner, A. 1974. "Recent results in the Shannon theory." IEEE Transactions on Information Theory 20(1): 2-10. 